$J R R D-1$ -

\title{
Effect of oculomotor rehabilitation on vergence responsivity in mild traumatic brain injury
}

\author{
Preethi Thiagarajan, BS Optom, MS, PhD; Kenneth J. Ciuffreda, OD, PhD \\ Department of Biological and Vision Sciences, State University of New York College of Optometry, New York, NY
}

\begin{abstract}
A range of dynamic and static vergence responses were evaluated in 12 individuals with mild traumatic brain injury (age: $29+/-3 \mathrm{yr}$ ) having near vision symptoms. All measures were performed in a crossover design before and after oculomotor training (OMT) and placebo (P) training. Following OMT, peak velocity for both convergence and divergence increased significantly. Increased peak velocity was significantly correlated with increased clinically based vergence prism flipper rate. Steady-state response variability for convergence reduced significantly following OMT. The maximum amplitude of convergence, relative fusional amplitudes, and near stereoacuity improved significantly. In addition, symptoms reduced significantly, and visual attention improved markedly. None of the measures were found to change significantly following $\mathrm{P}$ training. The significant improvement in most aspects of vergence eye movements following OMT demonstrates considerable residual brain plasticity via oculomotor learning. The improved vergence affected positively on nearwork-related symptoms and visual attention.
\end{abstract}

Key words: acquired brain injury, mild traumatic brain injury, nearwork symptoms, neuroplasticity, oculomotor dysfunction, oculomotor learning, oculomotor rehabilitation, traumatic brain injury, vergence, vergence dysfunction, visual attention.

\section{INTRODUCTION}

Traumatic brain injury (TBI) is defined as any structural damage caused by an external force to the brain and its associated structures (e.g., cranium) resulting in physiological disruption of brain function [1]. The Centers for Disease Control and Prevention estimated that approximately 1.7 million people have experienced a TBI in the
United States, with it being the leading cause of death and disability [2]. TBI is a major medical, optometric, social, economic, and public health issue in the United States [3]. Motor vehicle accidents, falls, assaults, sports-related concussion, gunshot wounds, work-related injuries, etc., are some of the most common causes of TBI [1], with 70 to 80 percent of all TBI being classified as mild TBI (mTBI) $[1,4]$.

Based on the severity and location of the injury, TBI results in a spectrum of dysfunctions involving sensory, motor, perceptual, physical, behavioral, cognitive, linguistic, and emotional aspects [5]. Being a primary modality of sensation, vision and its deficits following TBI will likely have an adverse effect on many activities of daily living (ADLs). Due to the pervasive nature of TBI (e.g.,

\footnotetext{
Abbreviations: $\Delta=$ prism diopter, $\mathrm{ADL}=$ activity of daily living, $\mathrm{BI}=$ base-in, $\mathrm{BO}=$ base-out, $\mathrm{CI}=$ convergence insufficiency, CISS $=$ Convergence Insufficiency Symptom Survey, LED = light-emitting diode, $\mathrm{mTBI}=$ mild traumatic brain injury, $\mathrm{NFV}=$ negative fusional vergence, $\mathrm{NPC}=$ near point of convergence, $\mathrm{OMT}=$ oculomotor training, $\mathrm{OR}=$ oculomotor rehabilitation, $\mathrm{P}=$ placebo, $\mathrm{PFV}=$ positive fusional vergence, $\mathrm{PRII}=$ Power Refractor II, SEM = standard error of mean, SS = steadystate, $\mathrm{SUNY}=$ State University of New York, TBI = traumatic brain injury, VSAT $=$ Visual Search and Attention Test.

*Address all correspondence to Preethi Thiagarajan, BS Optom, MS, PhD; Department of Biological and Vision Sciences, State University of New York College of Optometry, 33 West 42nd St, New York, NY 10036; 212-938-5768; fax: 212-938-5760. Email: pthiagarajan@sunvopt.edu http://dx.doi.org/10.1682/JRRD.2012.12.0235
} 
coup-contrecoup), numerous vision-related areas can be adversely affected $[3,6]$. For example, approximately 90 percent of individuals with mTBI having vision-related symptoms examined in an optometric clinic setting were diagnosed with one or more oculomotor dysfunctions following their acute care phase and natural recovery period [7]. Of the sample population, 70 percent manifested nonstrabismic types of oculomotor deficiencies involving version, vergence, and accommodation. Such deficits could adversely affect reading and other nearwork ADLs [8]. Identifying these abnormalities and rehabilitating them are essential in improving reading ability and overall quality of life [8]. In this article, only the oculomotor system subcomponent of vergence is considered.

Vergence refers to the disjunctive movement of the eyes used to track objects varying in depth over the range of one's binocular visual field [9]. The goal is to rapidly obtain and maintain fusion, or singleness, of the object of interest by placing the foveally bifixated object on corresponding retinal points within Panum's fusional area [10]. Furthermore, the vergence system acts in synchrony and precision with the versional system to track objects laterally in one's visual space accurately and singly, with the accommodative system continuously activated to maintain target clarity [10].

There are several separate subsystems believed to be involved in the neural control of vergence [11]. While the midbrain comprises the majority of neurons [12], evidence for the existence of neurons that also discharge during vergence have been located in the pons [13-14], cerebellum [15], and some areas of the cerebral cortex, such as the frontal eye field [16], parietal lobe [17-18], middle temporal [19] and medial superior temporal visual areas [20], and primary visual cortex [21]. Since the vergence neural pathway is extensive, any injury to the multitude of related brain and contiguous structures may adversely affect the vergence system.

\section{REVIEW OF VERGENCE DYSFUNCTIONS IN TRAUMATIC BRAIN INJURY}

\section{Clinical Studies}

\section{Retrospective Studies}

Five retrospective studies have assessed the prevalence of oculomotor abnormalities in patients with mTBI, both in a civilian clinic population and in Department of
Veterans Affairs and military populations [7,22-25]. The results are remarkably similar across these populations, in which the etiology of the TBI included both blast and nonblast injuries. Vergence dysfunctions ranged from 24 to 48 percent. While convergence insufficiency (CI) was the main clinical vergence dysfunction $(42.5 \%)$, other vergence deficits that were also found with a relatively high frequency included binocular instability $(10.0 \%)$, convergence excess $(2.5 \%)$, basic exophoria $(2.5 \%)$, and divergence insufficiency $(<2.0 \%)$ [7]. These general findings have been confirmed in four recent related investigations [26-29].

\section{Clinical Studies Involving Nonstrabismic Vergence Dysfunctions}

One of the earliest formal studies on the presence of binocular vision abnormalities following TBI was by Cross in 1945 [30]. Observations were made from several hundred cases examined at a military hospital. Convergence dysfunction was found to be one of the most common oculomotor anomalies. General body fatigue following TBI was presumed to be the cause of reported "ocular muscle fatigue," thus resulting in "defective convergence" in these individuals [30-31].

A number of more recent studies conducted in clinic populations have evaluated vergence function following TBI [32-39]. These studies have also found a range of vergence dysfunctions, including CI, reduced fusional ranges, and increased near exophoria, with percentages ranging from 25 to 75 percent.

\section{Laboratory Investigations}

An early study by Ron et al. objectively recorded vergence eye movements to a constant-velocity ramp stimulus, in which 28 patients with unspecified categories of TBI binocularly tracked a small target at near that moved continuously in depth from 30 to $5 \mathrm{~cm}$ along their midline [40]. Abnormal dynamic vergence responses were found in 71 percent of patients.

More recently, a wide range of static and dynamic vergence parameters were tested in 21 visually symptomatic adult patients with mTBI (mean \pm 1 standard error of mean [SEM] age: $45.7 \pm 3.1 \mathrm{yr}$ ), as related to nearwork, by the State University of New York (SUNY) acquired TBI research group [41]. Five static parameters were found to be significantly different and abnormal between the $\mathrm{mTBI}$ and the visually nondisabled groups: near point of convergence (NPC) break and recovery values were 
receded, positive fusional vergence (PFV) break and recovery values were reduced, and the stereoacuity threshold was elevated (presumably related to inaccurate vergence) in the group with mTBI [10]. While the transient response amplitudes for convergence and divergence did not differ significantly between the nondisabled subjects and those with mTBI, because they were already normal at baseline, all of the dynamic parameters (i.e., peak velocity, time constant, and latency) were significantly different $(p<0.05)$ between the two groups for both convergence and divergence. Responses were all slowed, delayed, and more variable in the group with mTBI than the nondisabled group.

Lastly, in a recent pilot study, objective recordings of vergence were obtained in two young adults with selfreported mTBI and nearwork symptoms [42]. Vergence dynamics were markedly slowed (i.e., reduced peak velocity) for convergence but not for divergence, as has been found earlier in larger populations [42].

\section{OVERVIEW OF OCULOMOTOR REHABILITATION IN TRAUMATIC BRAIN INJURY}

Several clinical case studies and a few population studies have evaluated the effect of oculomotor rehabilitation (OR) in mTBI. One of the earliest studies involved with the treatment of vergence and accommodative disorders was conducted by Chandler in a hospital-based setting in a series of World War II-related TBI cases $(n=33)$ [43]. OR (unspecified, but presumably "orthoptic" fusional training) commenced anywhere from $3 \mathrm{wk}$ to $5 \mathrm{yr}$ postinjury. While 73 percent of the patients treated were either fully remediated or markedly improved, 12 percent failed to improve and only 6 percent exhibited spontaneous recovery (from $3 \mathrm{~d}$ to $2 \mathrm{wk}$ postinjury). These results are consistent with later studies [44-48]. Evidence to support the fact that carefully programmed OR remediates binocular vision anomalies in those with mTBI also comes from several clinical population studies [38-39,49]. In each study, reading difficulty was one of the most common symptoms.

From these studies, there is abundant evidence from the literature in both laboratory-based and clinically based studies supporting the notion that targeted, specific, programmed OR procedures, which all incorporate the principle of motor learning [50-51], can remediate patients with a range of binocular vision disorders as a consequence of mTBI. Symptoms were ameliorated concurrent with improvement or normalization of clinical signs. This is important information because improved oculomotor abilities and related visual-perceptual skills can hasten progress in the patient's other rehabilitative programs [52-53]. This includes cognitive therapy, for example, which requires complex visual saccadic scanning and fine detail discrimination.

The purpose of the current investigation was to evaluate comprehensively clinically and laboratory-based vergence parameters in individuals with mTBI reporting nearwork-related symptoms of an oculomotor nature before and after oculomotor training (OMT) performed in the clinic, without a home-based component. The OMT involved all three main oculomotor subsystems: vergence, accommodation, and version. The measures were also compared after placebo (P) training. For the purpose of the present article, only the oculomotor subsystem of vergence is considered.

\section{METHODS}

\section{Subjects}

Twelve subjects ( 8 females and 4 males) between the ages of 23 and $33 \mathrm{yr}$ (mean \pm standard deviation: $29 \pm$ $3 \mathrm{yr}$ ) participated in the study (see Appendix 1 [available online only] for demographics). The training effects for the study were hypothesized to be moderate to large based on our earlier related laboratory studies [8,54-55], as well as the extensive clinical experience of the second author (K.J.C.). Sample size was calculated using a power analysis program $\left(\mathrm{G}^{*}\right.$ Power 3 ; Institut für Experimentelle Psychologie, Heinrich Heine Universität Düsseldorf, Düsseldorf, Germany) at an alpha level of 0.05, with a power set at 0.80 using two key parameters of vergence (i.e., NPC and peak velocity). All subjects had documented mTBI, with injury onset of greater than $1 \mathrm{yr}$ (1-10 yr postinjury) to avoid possible contamination from the natural recovery process [56]. All manifested several nearwork-related symptoms (e.g., intermittent diplopia) and at least one clinical sign of vergence dysfunction (e.g., receded NPC) of an oculomotor nature. All had stable general health. None had a significant cognitive dysfunction. Subjects were identified by their university-based healthcare provider and were recruited from the Raymond J. Greenwald Vision Rehabilitation 
Center at the SUNY College of Optometry University Optometric Center of New York. Subjects received a comprehensive vision examination prior to participating in the experiment, which included a detailed refractive, oculomotor, and ocular health assessment.

\section{Study Design}

We conducted a crossover, interventional experimental design of a single-blind nature (for the subject) (Figure 1). In this design, each subject acted as his or her own control, thus negating undesirable intersubject variability. Each subject received both OMT (treatment A) and $\mathrm{P}$ training (treatment $\mathrm{B}$ ). During phase 1, every oddnumbered subject first received treatment $\mathrm{A}$, every evennumbered subject first received treatment $\mathrm{B}$, and vice versa during phase 2 . This interventional study had a duration of $15 \mathrm{wk}$. It consisted of $12 \mathrm{wk}$ of the two treatment phases, 6 wk each phase separated by $1 \mathrm{wk}$, for a total of $9 \mathrm{~h}$ of OMT and $9 \mathrm{~h}$ of $\mathrm{P}$ training. In addition, there was a 3 wk measurement period: 1 wk before phase 1 treatment, $1 \mathrm{wk}$ after phase 1 treatment, and $1 \mathrm{wk}$ after phase 2 treatment. During these training and measurement periods, subjects did not perform any other OR to avoid contamination of test results.

The study consisted of the following phases:

1. Week 1: Initial baseline measures - all evaluative procedures (described later) were recorded over two separate test sessions (each session lasting for up to $1.5 \mathrm{~h}$, including rest periods to prevent fatigue), each separated by at least $2 \mathrm{~d}$.

2. Weeks 2-7: Phase 1 treatment -6 wk of either OMT or $\mathrm{P}$ training. Subjects received two training sessions per

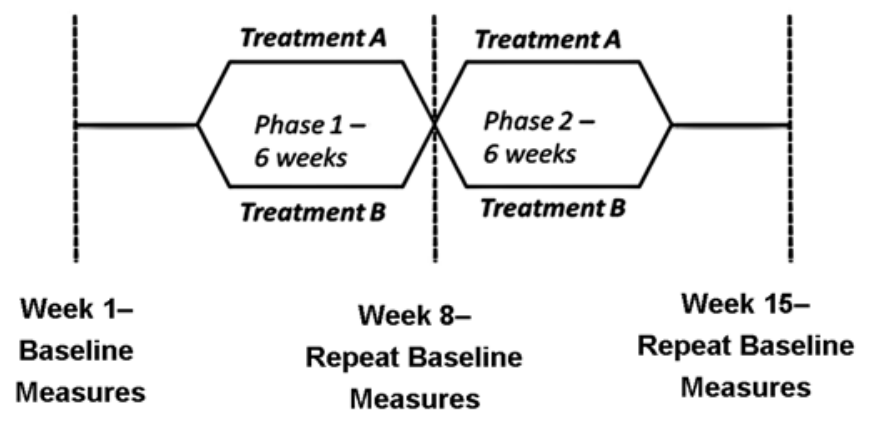

Figure 1.

Illustration of crossover interventional experimental design and treatment phases. Adapted from Thiagarajan [87]. week. Each session was 60 min in duration, involving 45 min of actual training with the remainder of time consisting of short and interspersed rest periods for the subject. Total training time was $9 \mathrm{~h}$ over the $6 \mathrm{wk}$.

3. Week 8: Repeat baseline measures - same as step 1 .

4. Weeks 9-14: Phase 2 treatment-same as step 2.

5. Week 15: Repeat baseline measures-same as step 1 .

\section{Evaluative Procedures}

Several general areas of testing were performed; these included clinical and laboratory vergence measures, as well as visual attention and near-vision symptoms. All clinical measures were assessed using standardized clinical techniques [57]. All laboratory-based objective measures were performed using commercially available instrumentation with well-established test protocols developed in our laboratory for version [54], accommodation [58], and vergence [41]. All measures were noninvasive and were recorded with the subject's habitual distance correction in place. Order of testing was randomized over the $2 \mathrm{~d}$ of measurements.

1. Clinical measures: Selected binocular vision-related parameters were tested with randomization under standard clinical room illumination (80 Lux). They included NPC break and recovery, horizontal near phoria using the von Graefe prism dissociation method, horizontal near PFV and negative fusional vergence (NFV) ranges, vergence prism facility (with 12 prism diopter $[\Delta]$ base-out $[\mathrm{BO}]$ and $3 \Delta$ base-in $[\mathrm{BI}]$ prism flippers), and stereoacuity using the Titmus stereo test.

2. Laboratory-based objective measures: Vergence dynamics to symmetric step vergence stimuli was recorded using the Power Refractor II (PRII) (Plusoptix Inc; Atlanta, Georgia) based on the principle of infrared videography and dynamic retinoscopy, with a sampling rate of $12.5 \mathrm{~Hz}$ (resolution: $<0.9^{\circ}$ ) for binocular recording, as described elsewhere [41]. This sampling rate exceeds the Nyquist criterion [59]. Targets comprised the contiguous red and green fixation light-emitting diodes (LEDs) (angular size: $0.28^{\circ}$ ) located on the measuring head of the PRII at $1 \mathrm{~m}$ and a white LED (angular size: $0.86^{\circ}$ ) placed at $0.3 \mathrm{~m}$, both aligned along the midline. Mean response amplitude, peak velocity, time constant, and steady-state (SS) response variability were calculated separately for both convergence and divergence.

3. Subjective visual attention test: A subjective correlate of global visual attention was assessed using the Visual 
Search and Attention Test (VSAT). It involves a search (for a letter or a symbol) and cancellation (cross-out) task that was developed by Trenerry et al. [60]. The VSAT was performed binocularly at the subject's habitual nearwork distance. Percentile scores were calculated from the age-matched normative table for the two test sheets.

4. Symptom scale: Individual symptoms related to nearwork were rated by the subjects using the Convergence Insufficiency Symptom Survey (CISS) [61]. It is composed of a 15 -item questionnaire probing readingrelated symptoms (e.g., intermittent diplopia). The severity of symptoms is scaled from 0 to 4 , i.e., from least symptomatic to most symptomatic. The total score was compared before and after each of the two training phases. A reduction in overall score of $\geq 10$ was considered to reflect a significant reduction of symptoms. A score of $\leq 16$ was considered to represent being relatively asymptomatic.

\section{Treatment Protocol}

\section{Treatment A: Oculomotor Training}

OMT was performed along the midline at $0.4 \mathrm{~m}$, two sessions per week, for a total of $6 \mathrm{wk}$. OMT was performed with constant verbal and visual feedback, motivation, and repetition and involved active participation of the subject to maximize attention. At a session, each oculomotor component (version, vergence, and accommodation) was trained for $15 \mathrm{~min}$, interspersed with 5 min rest periods. Each session lasted for $1 \mathrm{~h}$, with $45 \mathrm{~min}$ of training and $15 \mathrm{~min}$ of rest periods, for a total of $9 \mathrm{~h}$ of training over the $6 \mathrm{wk}$ OMT phase, $3 \mathrm{~h}$ for each oculomotor subsystem. For the purpose of the present article, however, only the vergence training and related results are discussed (Table 1).

For step vergence amplitude training, BO and BI prisms were used. The basic principle behind the training was to maintain the accommodative demand constant at $0.4 \mathrm{~m}(2.5 \mathrm{D})$, while increasing the vergence demand $[57,62]$. The fusional targets were composed of pictures, symbols, numbers, letters, tumbling E, and colors displayed on a computer screen at $0.4 \mathrm{~m}$. As treatment progressed and the subject demonstrated improvement, task difficulty was increased by reducing target size (from $10^{\circ}$ to $2^{\circ}$ ) and manually increasing the vergence demand prismatically. The total amount of prism depended on the subject's task performance level. After introducing each BO prism, subjects were instructed to fuse the target as rapidly
Table 1.

Training protocol for vergence.

\begin{tabular}{llcc}
\hline \multicolumn{1}{c}{ Stimulus } & \multicolumn{1}{c}{$\begin{array}{c}\text { Stimulus } \\
\text { Parameter }\end{array}$} & $\begin{array}{c}\text { Training } \\
\text { Period } \\
\text { Duration } \\
\text { (min) }\end{array}$ & $\begin{array}{c}\text { Total } \\
\text { Training } \\
\text { Duration } \\
(\mathbf{m i n})\end{array}$ \\
\hline Disparity & Step Amplitude (BO/BI) & 7 & 15 \\
& Step Facility (BO/BI) & 5 & \\
No Disparity & Ramp & 3 & \\
& Placebo-Step & 10 & 15 \\
& Placebo-Ramp & 5 & \\
\hline BI = base-in, BO = base-out. & & \\
\hline \hline
\end{tabular}

as possible. This trained the fast vergence mechanism [63]. The fused percept was then maintained for 15 to $20 \mathrm{~s}$. This sustained viewing trained the slow vergence mechanism that maintained the vergence response [63]. Such response maintenance reflects the vergence adaptation mechanism [63-64]. BO training was terminated at the point at which subjects could no longer fuse (and/or focus) with their maximum effort. This was repeated for BI prisms, which stimulated relative divergence. The order of $\mathrm{BO}$ and $\mathrm{BI}$ training at each session was randomized.

For step vergence facility training [62], combinations of $\mathrm{BO}$ and $\mathrm{BI}$ prism flippers $(3 \Delta \mathrm{BO} / 1 \Delta \mathrm{BI}, 6 \Delta \mathrm{BO} / 2 \Delta \mathrm{BI}$, $9 \Delta \mathrm{BO} / 3 \Delta \mathrm{BI}$, and $12 \Delta \mathrm{BO} / 3 \Delta \mathrm{BI})$ were used while maintaining accommodation constant at $0.4 \mathrm{~m}(2.5 \mathrm{D})$. The fusional targets were similar to those used in the previously mentioned amplitude training. Based on the subject's initial ability to fuse, the magnitude of prism flipper was chosen. Subjects bifixated targets on a computer screen, and they were instructed to fuse and focus as rapidly as possible and to achieve the maximum number of cycles possible. As the treatment progressed and the subject demonstrated improvement, task difficulty was increased by increasing the prism flipper magnitude and by reducing target size (from $10^{\circ}$ to $2^{\circ}$ ).

For ramp vergence training, subjects binocularly tracked an isolated, high-contrast ( $>90 \%$ ), Snellen $20 / 30$ letter controlled by an XY plotter and function generator moving continuously over a range of 0.5 to $0.2 \mathrm{~m}$ at the rate of 0.1 to $1.0 \mathrm{~Hz}$. Task difficulty was increased by tracking at closer distances, with the combination of increased speed. Subjects were instructed to maintain the target clear and single.

\section{Treatment B: Placebo Training}

$\mathrm{P}$ training was performed as described previously for OMT. P training did not involve any disparity stimulation, 
because this is the primary drive for the vergence system [10]. For the P-step, binocular and monocular plano-powered loose prism and prism flippers and/or monocular vertical prism $(0.5$ or $1 \Delta \mathrm{D})$ flippers were used as the $\mathrm{P}$ training analog to OMT. Training was performed both monocularly (5 min) and binocularly (5 min). For the Pramp, subjects tracked a difference of Gaussian (0.2 cycles $/{ }^{\circ}$ ) target through a $0.5 \mathrm{~mm}$ pinhole monocularly for $5 \mathrm{~min}$ (2.5 min each eye) in an otherwise darkened room, which did not provide any disparity (or blur or accommodative vergence) drive [10].

\section{Data Acquisition and Analyses for Objective Recordings}

The recorded video files were saved to the PRII hard drive and converted into .txt files. They were then transferred into Excel (Microsoft; Redmond, Washington) for detailed analysis. Three artifact-free (free of blinks and/or saccades) convergence and three divergence responses were selected for analysis from the right eye position traces for each subject from a sample of seven to eight responses in each direction. The middle three responses were used for analysis, and the initial and final responses were omitted to avoid possible learning and fatigue effects, respectively [41]. An exponential decay function was fit to the traces, and the response amplitudes and time constants were obtained using GraphPad Prism (GraphPad Software Inc; La Jolla, California). The peak velocities were derived from first-order differentiation of the exponential equation. The SS response variability was calculated from the standard deviation of the measured time window $(\sim 5 \mathrm{~s})$ of response after SS was attained. The goodness of fit was assessed from the $r^{2}$ values of each fitted response. The mean $r^{2}$ value for both increasing and decreasing steps was always $>0.8$ for each subject, thus demonstrating a good fit. The mean amplitude, time constant, and peak velocity of the responses at baseline, postOMT, and post-P training were compared statistically using GraphPad Prism at $p \leq 0.05$.

\section{STATISTICAL ANALYSES}

\section{Combined Group}

The key objective of the study was to evaluate the effect of OMT in individuals with mTBI and oculomotorbased near-vision symptoms. Therefore, the main analyses included a comparison of baseline measures before and after OMT using paired two-tailed $t$-tests. Data from all 12 subjects were analyzed and presented as the "com- bined group" results. For those subjects who received OMT first, baseline measures from week 1 (baseline) and baseline measures from week 8 (post-OMT) were used for the analyses. For those subjects who received $\mathrm{P}$ training first, baseline measures from week 1 (baseline) and baseline measures from week 15 (post-OMT) were used for analyses. For subgroup analyses, a repeated-measures, one-way analysis of variance and Tukey post hoc analyses were performed for comparisons between baseline, OMT, and P training. In addition, correlations between relevant objective and subjective parameters were performed using linear regression.

\section{Subgroups}

See Appendix 2 (available online only) for detailed subgroup analyses.

\section{RESULTS (COMBINED GROUP ANALYSIS)}

\section{Laboratory-Based Objective Measures}

The dynamic trajectories of the symmetric vergence responses from the right eye were fit using an exponential, one-phase decay function. There was a significant increase in peak velocity for both convergence $(t(11)=$ $3.08 ; p=0.01)$ and divergence $(t(11)=3.96 ; p=0.01)$ following OMT, but it did not normalize (Figure 2(a)). There was a significant decrease in time constant for both convergence $(t(11)=2.77 ; p=0.01)$ and divergence $(t(11)=$ 3.65; $p=0.01$ ) after OMT (Figure 2(b)). While the time constant normalized for convergence, it did not for divergence. Figure 3 shows the exponential fit to vergence responses in a typical subject with mTBI. Faster convergence and divergence responses are evident following OMT. Convergence SS response variability reduced significantly $(t(11)=2.28 ; p=0.04)$ after OMT, but it did not for divergence $(t(11)=0.62 ; p=0.54)$. There was no significant difference in response amplitudes for either convergence $(t(11)=0.80 ; p=0.43)$ or divergence $(t(11)=$ $0.41 ; p=0.99)$, because they were already accurate at baseline. See Table 2 for group mean $( \pm 1$ SEM) dynamic values at baseline and post-OMT. Of the eight parameters that were abnormal at baseline, six (75\%) improved significantly following OMT. The remaining two parameters were already normal at baseline.

\section{Clinically Based Subjective Measures}

Of the nine clinical parameters assessed, five were already normal at baseline, and four were found to be 
(a)

\section{COVERGENCE}

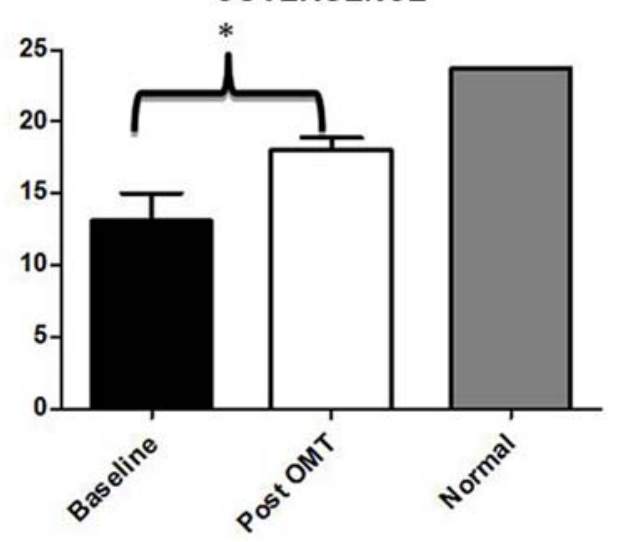

(b)

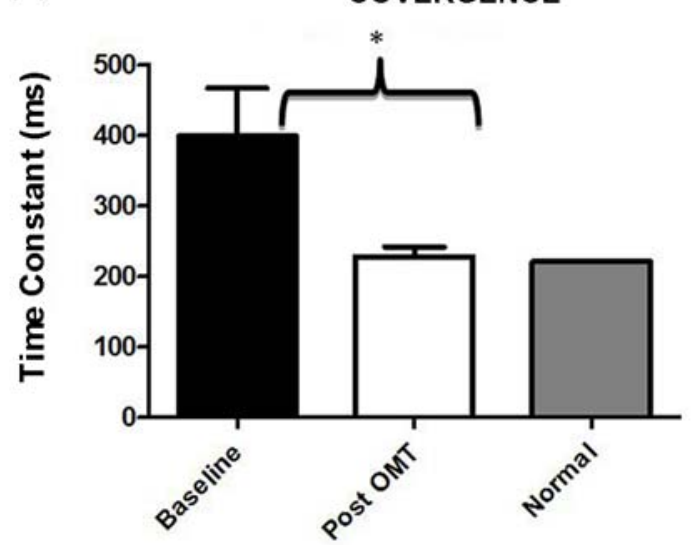

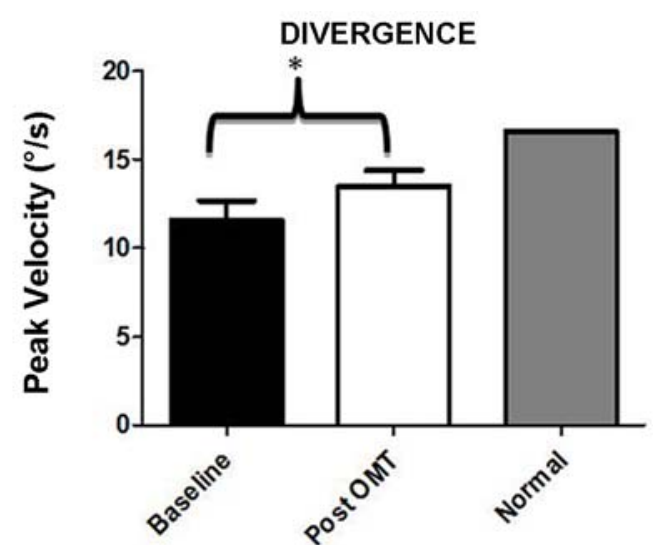

DIVERGENCE

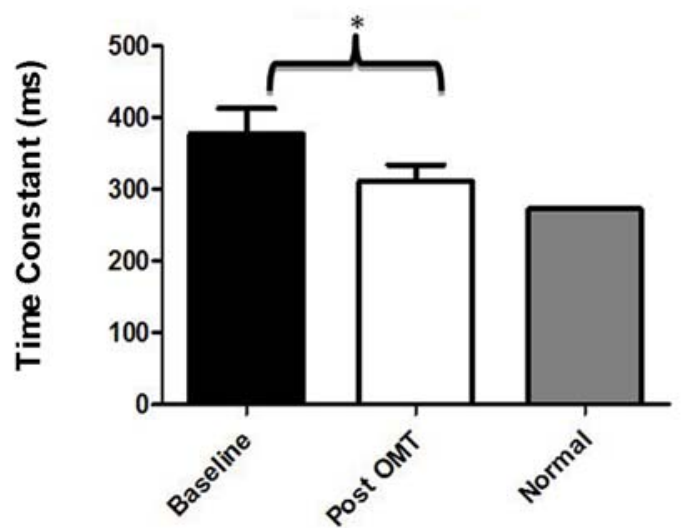

Figure 2.

(a) Peak velocity for convergence and divergence before and after oculomotor training (OMT) in comparison with mean normal value for this response amplitude derived from Yuan et al. [75]. (b) Time constant for convergence and divergence before and after OMT in comparison with mean normal value derived from Ciuffreda et al. [48]. Error bar indicates +1 standard error of mean. *Significantly different.

abnormal. All four abnormal parameters (100\%) improved significantly following OMT. There was a significant decrease (i.e., improvement) in both the NPC break $(t(11)=4.07 ; p=0.01)$ and NPC recovery $(t(11)=$ 3.64; $p=0.01$ ) after OMT, but they did not normalize (Figure 4(a)). In addition, this increase in maximum vergence amplitude (NPC break) was significantly correlated $(p<0.05)$ with reduction in symptoms $(r=0.57)$, as well as with improved visual attention $(r=0.40)$. Both the PFV break $(t(11)=2.80 ; p=0.01)$ and PFV recovery $(t(11)=4.71 ; p=0.01)$ values significantly increased with OMT. Prism vergence facility $(t(11)=4.22 ; p=$ 0.01 ) (Figure 4(b)) and stereoacuity $(t(11)=2.34 ; p=$ 0.03 ) also improved significantly following OMT. The NFV break increased significantly $(t(11)=3.40 ; p=$
0.01 ) and normalized, while the NFV recovery exhibited a predicted trend $(t(11)=2.04 ; p=0.06)$. There was no significant change in the horizontal near phoria value $(t(11)=0.49 ; p=0.62)$, which ranged from 14 exophoria to 1 esophoria in the group. See Table 3 for the group mean $( \pm 1$ SEM) values at baseline and post-OMT.

There was no statistically significant effect $(p>0.05)$ of the P training on any of the vergence parameters tested. See Appendix 2 (available online only) for details.

\section{Other Subjective Tests}

The CISS total score significantly reduced $(t(11)=$ $3.69 ; p=0.01$ ) from a mean value of $37 \pm 4$ to $28 \pm 3$ following OMT. This quantitatively indicated a reduction in nearvision-related symptoms following OMT. 

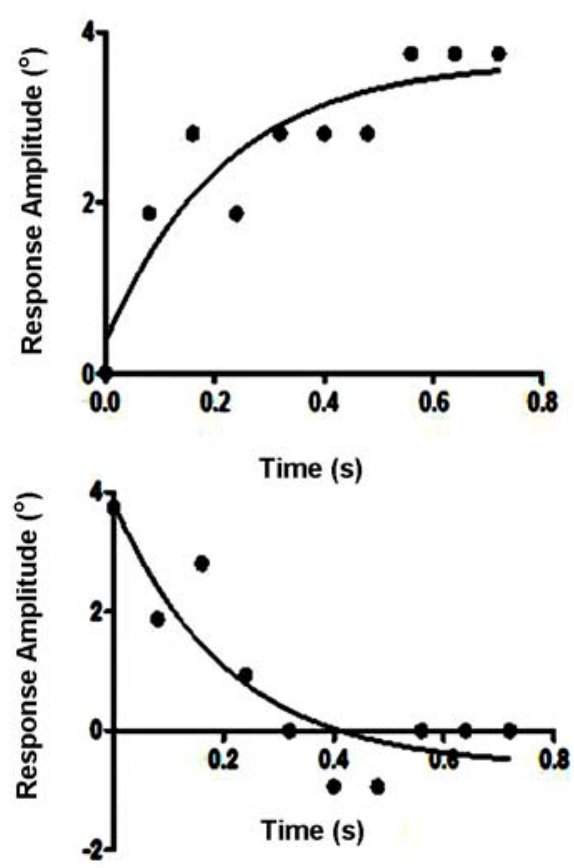
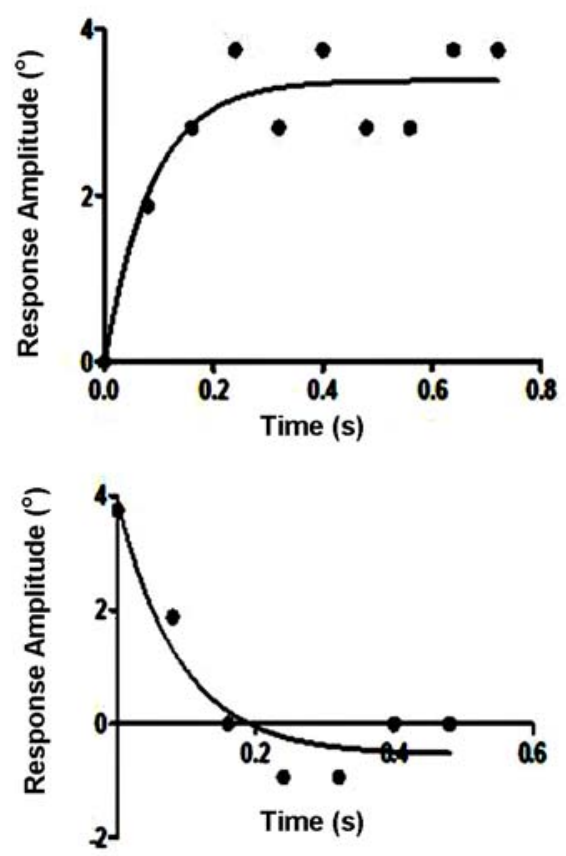

Figure 3.

Horizontal eye position as function of time. Exponential fit of step vergence dynamic trajectory from right eye before (left column) and after (right column) oculomotor training for convergence (top row) and divergence (bottom row) in typical subject with mild traumatic brain injury.

Table 2.

Mean \pm 1 standard error of mean laboratory-based objective parameters of symmetric vergence before (baseline) and after oculomotor training (post-OMT).

\begin{tabular}{llcc}
\hline \multicolumn{1}{c}{ Dynamic Parameter } & Baseline & Post-OMT & p-Value \\
\hline C: Peak Velocity ( $/ \mathrm{s})$ & $13.0 \pm 1.9$ & $18.0 \pm 0.9$ & $0.01^{*}$ \\
D: Peak Velocity ( $/ \mathrm{s})$ & $11.6 \pm 1.1$ & $13.5 \pm 0.8$ & $<0.01^{*}$ \\
C: Time Constant (ms) & $399 \pm 68$ & $228 \pm 14$ & $0.01^{*}$ \\
D: Time Constant (ms) & $378 \pm 35$ & $312 \pm 22$ & $<0.01^{*}$ \\
C: SS Variability $\left(^{\circ}\right)$ & $0.90 \pm 0.07$ & $0.75 \pm 0.04$ & $0.04^{*}$ \\
D: SS Variability $\left({ }^{\circ}\right)$ & $0.81 \pm 0.05$ & $0.78 \pm 0.02$ & 0.54 \\
C: Response Amplitude $\left(^{\circ}\right)$ & $3.93 \pm 0.07^{\dagger}$ & $3.96 \pm 0.08$ & 0.43 \\
D: Response Amplitude $\left({ }^{\circ}\right)$ & $3.93 \pm 0.06^{\dagger}$ & $3.93 \pm 0.08$ & 1.00 \\
\hline
\end{tabular}

*Statistically significant.

${ }^{\dagger}$ Already normal at baseline.

$\mathrm{C}=$ convergence, $\mathrm{D}=$ divergence, $\mathrm{SS}=$ steady-state.

With respect to visual attention at baseline, the group mean VSAT percentiles increased significantly $(t(11)=$ $4.43 ; p=0.01)$ from the 32 nd $( \pm 9)$ to the 50th $( \pm 10)$ percentile following OMT, with increases in 10 of the 12 $(80 \%)$ subjects. This indicated quantitatively increased visual attentional aspects concurrent with OMT.

\section{DISCUSSION}

The primary aim of the present investigation was to evaluate a range of objective laboratory and subjective clinical measures of vergence before and after vergencebased OMT in individuals who reported nearwork-related 


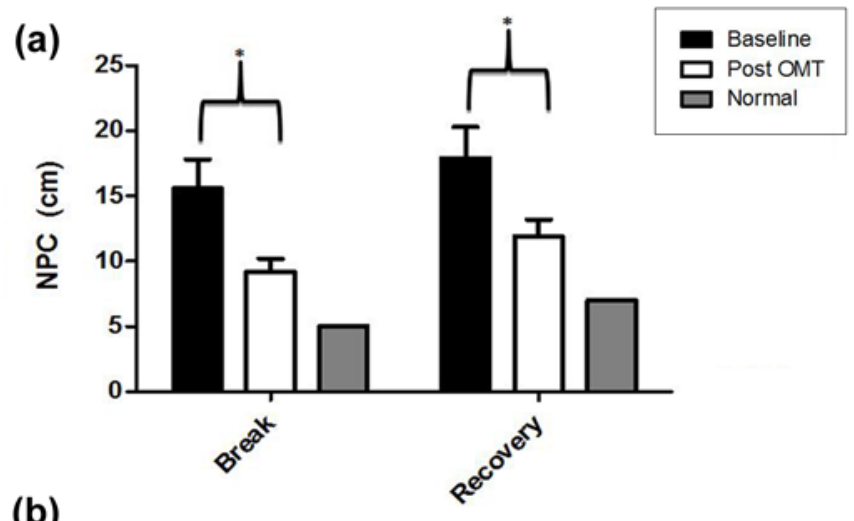

(b)

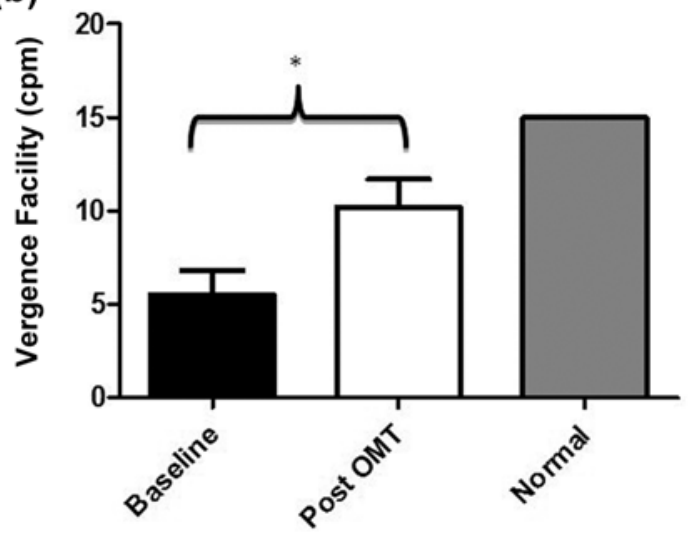

Figure 4.

(a) Mean near point of convergence (NPC) break and recovery values before and after oculomotor training (OMT) as compared with mean normal value derived from Manas [71]. (b) Mean vergence facility before and after OMT in mild traumatic brain injury as compared with mean normal value derived from Manas [71]. Error bar indicates +1 standard error of mean. *Significantly different.

symptoms of an oculomotor nature following their mTBI. With only $3 \mathrm{~h}$ of total vergence training distributed over 6 wk, significant $(p<0.05)$ improvements were found in the vast majority $(>80 \%)$ of the key laboratory and clinical aspects of vergence that were abnormal at baseline. The results were also compared with an equal dosage and distribution of $\mathrm{P}$ training. None of the vergence measures were found to have a significant group effect from the $\mathrm{P}$ training $(p>0.05)$.

Although most of the initially abnormal parameters significantly improved with OMT, many did not normalize. This may suggest that the OMT should be increased, perhaps twofold or greater, to obtain a yet more robust result, assuming that the underlying neurology is sufficiently intact to yield a normalization. This critical area needs to be explored in the future. Lastly, as discussed for dynamic OMT aspects, the question remains whether additional hours of training would yield normalization of all static vergence parameters. Future studies in this critical area are needed.

\section{Training Effect on Vergence Dynamics}

At baseline, both convergence and divergence eye movements consistently demonstrated slowed dynamic trajectories in all subjects. This was evident from the reduced peak velocity along with the correlated increased time constant values. The group mean peak velocity in the population with $\mathrm{mTBI}$ was reduced by $\sim 45$ percent for convergence and $\sim 25$ percent for divergence [65-66]. The slowed but accurate responses suggest the presence of normal visual feedback with respect to disparity detection and processing. This is consistent with both laboratory and modeling findings, suggesting the dual-mode control of vergence [67]. That is, the initial response component (i.e., the first $200 \mathrm{~ms}$ ) is preprogrammed (i.e., open-loop response) for the estimated amplitude of the step disparity input, followed by completion of the movement over the next several hundred milliseconds via visual feedback control (i.e., closed-loop response), with the overall response being completed in approximately 800 to $1,000 \mathrm{~ms}$. These findings suggest that the slowed but accurate responses were primarily the result of improvement in the pulse subcomponent of the neural signal and not caused by its step subcomponent.

Following OMT, there was a significant increase in peak velocity by $\sim 40$ percent for convergence and $\sim 15$ percent for divergence from their mean baseline value. Concomitantly, the time constant for both convergence and divergence exhibited correlated and proportional decreases, as expected due to their inverse interrelation.

The prism flipper facility rate is the clinical analog for the overall laboratory-based vergence response incorporating and combining all dynamic parameters (i.e., peak velocity, time constant, and latency) into a global, validated metric [62]. Thus, peak velocity and prism flipper rate were found to correlate significantly with each other both before and after the OMT. At baseline, the mean vergence facility rate was $\sim 65$ percent less than the mean clinic norm [62]. With OMT, subjects could now fuse both the BO and BI prisms rapidly, with a large and significant twofold increase in facility rate, but it did not normalize. 
Table 3.

Mean \pm 1 standard error of mean clinically based parameters of vergence before (baseline) and after oculomotor training (post-OMT).

\begin{tabular}{|c|c|c|c|}
\hline Clinical Parameter & Baseline & Post-OMT & $p$-Value \\
\hline$\overline{\text { NPC Break }(\mathrm{cm})}$ & $15.6 \pm 2.3$ & $9.2 \pm 1.0$ & $<0.01^{*}$ \\
\hline NPC Recovery $(\mathrm{cm})$ & $17.9 \pm 2.5$ & $11.9 \pm 1.3$ & $<0.01^{*}$ \\
\hline $\operatorname{PFV}$ Break $(\Delta)$ & $22.0 \pm 1.8^{\dagger}$ & $27.0 \pm 1.6$ & $0.01^{*}$ \\
\hline PFV Recovery $(\Delta)$ & $13.0 \pm 1.3^{\dagger}$ & $21.0 \pm 1.7$ & $<0.01^{*}$ \\
\hline $\operatorname{NFV}$ Break $(\Delta)$ & $16.5 \pm 1.6$ & $19.0 \pm 1.5$ & $<0.01^{*}$ \\
\hline NFV Recovery $(\Delta)$ & $10.5 \pm 1.2^{\dagger}$ & $12.3 \pm 1.1$ & 0.06 \\
\hline Stereoacuity (arc sec) & $26.2 \pm 1.5^{\dagger}$ & $22.9 \pm 1.1$ & $0.03^{*}$ \\
\hline CISS (score) & $37 \pm 4$ & $28 \pm 3$ & $<0.01^{*}$ \\
\hline VSAT $(\%)$ & $32 \pm 9$ & $50 \pm 10$ & $<0.01^{*}$ \\
\hline
\end{tabular}

*Statistically significant.

${ }^{\dagger}$ Already normal at baseline.

$\Delta=$ prism diopter, CISS $=$ Convergence Insufficiency Symptom Survey, exo $=$ exophoria, NFV $=$ negative fusional vergence, NPC $=$ near point of convergence, $\mathrm{PFV}=$ positive fusional vergence, $\mathrm{VSAT}=$ Visual Search and Attention Test.

In the present study, the SS response was assessed for $\sim 5 \mathrm{~s}$. Within this measured window of time, the SS variability for convergence decreased significantly following OMT as assessed at $30 \mathrm{~cm}$. This suggests improved convergence sustainability involving the slow vergence mechanism [63]. Our previous study in this area [41] found abnormal, reduced vergence adaptation in those with mTBI, which is also typically found in those without mTBI but with vergence-related dysfunction and correlated symptoms [68]. In contrast, the SS variability did not change markedly for divergence at the $1-\mathrm{m}$ test distance. This finding may not be surprising given the fact that the OMT was performed at the conventional near reading distance of $40 \mathrm{~cm}$. This suggests lack of generalization of the rehabilitation effects (i.e., oculomotor learning) to the overall vergence system. In the future, vergence training should also be conducted at different distances and gaze directions to attain a more generalizable improvement in vergence responsivity.

\section{Training Effect on Static Measures of Vergence}

The NPC is the main static diagnostic measure used in the clinic for assessment of vergence dysfunctions [62]. At baseline, the subjects with mTBI demonstrated markedly receded NPC components (break and recovery), thus suggesting poor maximal convergence amplitude fusional ability. Following OMT, the NPC amplitude and recovery improved significantly but did not normalize.

The relative vergence amplitude increased in both the convergent and divergent directions following OMT. This was evident from the increased PFV and NFV break val- ues. While the PFV recovery value significantly improved following OMT, it did not for the NFV recovery value. The relative vergence system has several response nonlinearities (e.g., amplitude, dynamics) between PFV and NFV [62], and this may reflect one such difference [66]. This is consistent with the fact that training relative convergence (PFV) is easier than relative divergence (NFV) [69]. It is also consistent with neurophysiological evidence demonstrating more convergence-related cells present than divergence-related cells [15].

The overall improvement in convergence ability was also reflected in the improved near stereoacuity with OMT. Presumably, this is caused by improvement in vergence response accuracy and stability, which would reduce the mean fixation disparity vergence error at near, hence improving stereoacuity [10]. This is consistent with the recent finding that increased fixation disparity was significantly correlated with reduced stereoacuity at near in individuals with mTBI [41].

However, OMT did not seem to have an effect on the near horizontal phoria. In the nonadapted state of vergence, this value reflects the horizontal position of eyes in the absence of fusional vergence [70]. This value would be expected to change only if the cross-link ratio (response accommodative convergence/accommodation) changed [71]. However, past studies have reported constancy of this cross-link following vergence training in both visually nondisabled subjects $[64,72]$ and in symptomatic individuals manifesting binocular vision dysfunction [73].

From the present findings, as well as from the previous studies that assessed objective and clinical measures of 
THIAGARAJAN and CIUFFREDA. Effect of oculomotor rehabilitation on vergence responsivity in mTBI

vergence, it appears that the laboratory-based peak velocity and clinically based prism flipper facility, along with NPC, are key diagnostic measures in the population with mTBI. This is consistent with recent suggestions in the literature based on the SUNY research group findings [41,74].

\section{Neurophysiological Implications}

Although several areas of the brain have been identified in the control of vergence, the midbrain houses the majority of vergence-related neurons [11]. The motoneuronal controller of vergence has been found to be somewhat similar to saccades, because the final neural signal consists of a small and broad pulse combined with a step [75-76]. The pulse signal, which is produced by the midbrain vergence "burst cells" that fire in relation to vergence velocity, is responsible for rapidly displacing the eyes in a time-optimal manner to a new binocularly fixated target position. In contrast, the step signal, which is produced by the vergence tonic cells that fire in relation to vergence angle, maintains the SS eye position (i.e., vergence angle) on the binocularly fixated target accurately [77]. A neural integrator (i.e., nucleus reticularis tegmenti pontis) [78-79] has been proposed to process the velocity signal to a step signal. Then, the combined signal is sent via the oculomotor neurons to innervate the extraocular muscles to make an appropriate vergence eye movement [11].

Based on the results of the present study at baseline, and earlier studies [41-42], the primary neural deficit in the patient with mTBI is believed to be the pulse. This is reflected in the consistently slowed dynamics (e.g., reduced peak velocity and increased time constant) for both convergence and divergence in the present study prior to OMT, which can be accounted for by a reduction in pulse height. Thus, the overall time course of the vergence dynamic trajectory was slowed. Since the appropriate vergence amplitude was eventually attained both before and after OMT, this suggests that the step component had the appropriate mean height. However, the subsequent vergence SS level exhibited increased variability, which suggests that the presence of increased neural noise could produce a more variable step signal. Tonic vergence cells constantly fire to maintain this SS level. The increased SS variability could reflect a higher degree of variability in the neural firing of such cells. Following OMT, the increased peak velocity can be attributed to an increase in pulse height (presumably because of the increased firing rate), thus resulting in faster motor responsivity to attain the final SS position. Following
OMT, the reduced SS variability during convergence could be attributed to reduced step gain variability as a result of normalization of tonic cells firing.

\section{Mechanisms of Neuroplasticity and Oculomotor Learning}

Under normal circumstances, repeated synaptic stimulation, along with its coincident activation, results in an increased synaptic strength and memory storage [80-82]. This experience-dependent neuroplasticity is composed of biochemical-, cellular-, physiological-, and structurallevel changes [83]. Recovery following an insult to the brain has been categorized as "spontaneous reorganization" (or natural recovery) and "training-induced recovery" [56]. The former occurs immediately following injury. It is believed to involve restoration of neurotransmission in the adjacent spared area and regions distant from the injury location. This natural recovery period following TBI occurs over the first 6 to 9 mo [84]. However, training-induced recovery appears to be relatively independent of the amount of time elapsed after the injury. Significant oculomotor improvements can occur even 5 to $10 \mathrm{yr}$ after the first injury [8]. This involves functional recovery via a "relearning" process. Remapping and reconfiguration of neural circuits both within and across relevant regions play a significant role in the recovery process [83].

Following TBI, the decreased vergence response peak velocity may be attributed to diffuse axonal injury. The compromised white matter integrity causes slowed conduction of nerve impulses [85-86], thus resulting in an overall slowed response (e.g., slowed vergence). In addition, the decreased number of synapses, reduced firing rate, reduced neural synchrony, and lack of correlation within and across the specific brain regions cause loss of automaticity and an overall reduction in the system's maximum amplitude (e.g., NPC) [42]. Figure 5 shows the schematic representation of the proposed neurological mechanisms involved based on the aforementioned laboratory findings.

OMT acts as a relearning process, in which the system being trained or conditioned regains its automaticity through repetition, which then becomes preprogrammed with much practice. In the present study, an overall improvement in oculomotor behavior was observed in all individuals with mTBI. It is believed to be a consequence of "oculomotor learning" involving the relearning processes described earlier [83]. Figure 6 shows the schematic representation of the proposed mechanisms of OR based on 


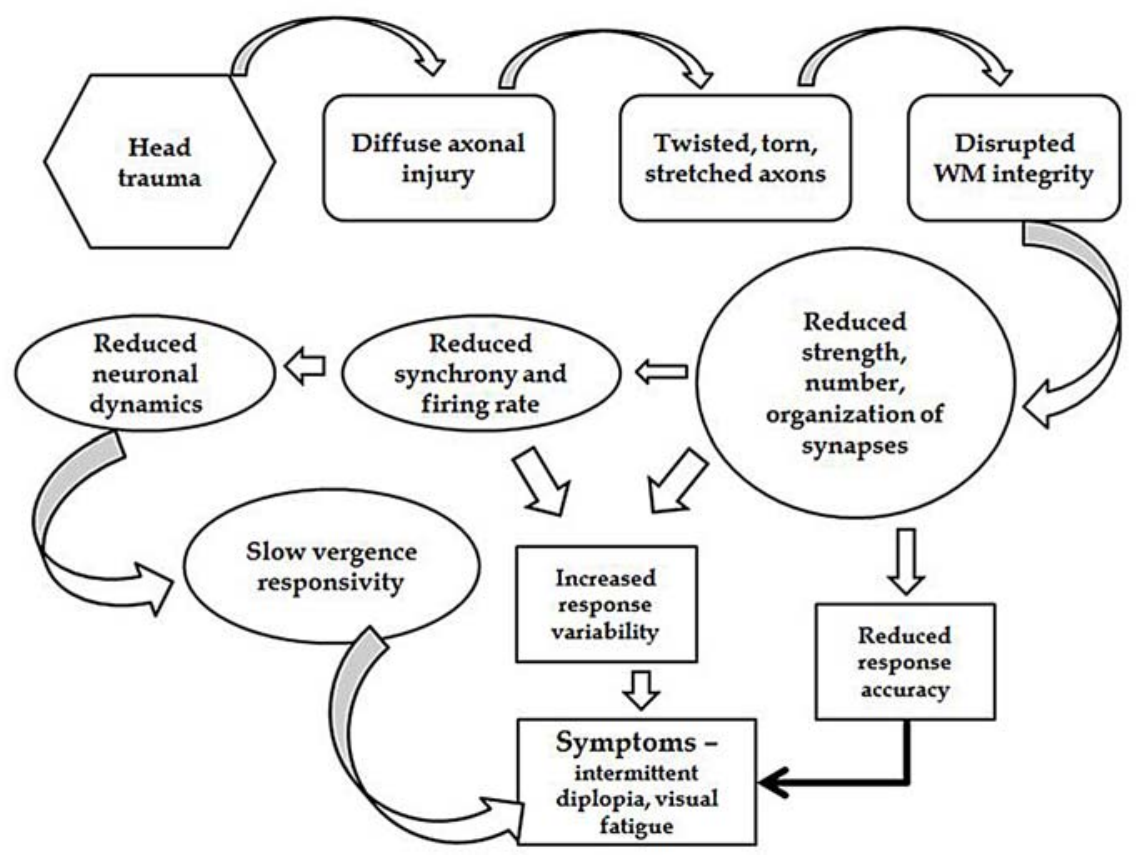

Figure 5.

Proposed neural mechanisms of traumatic brain injury causing vergence dysfunction. $\mathrm{WM}=$ white matter.

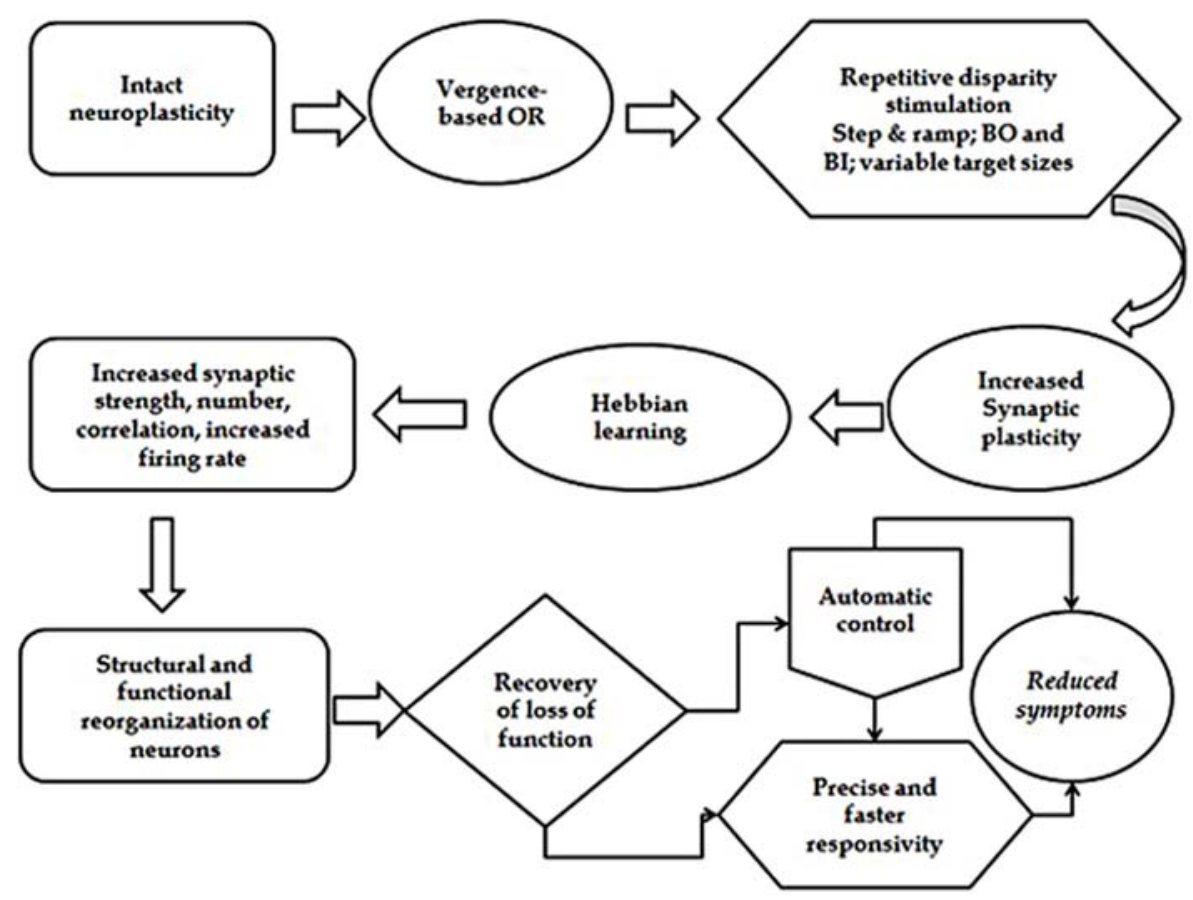

Figure 6.

Proposed underlying mechanisms of vergence-based oculomotor rehabilitation $(\mathrm{OR})$. $\mathrm{BI}=$ base-in, $\mathrm{BO}=$ base-out. 
THIAGARAJAN and CIUFFREDA. Effect of oculomotor rehabilitation on vergence responsivity in mTBI

the aforementioned laboratory findings. A combination of repeated stimulation with various amounts and types of disparity (crossed and uncrossed), increasing task-level difficulty, active participation of the subjects, increased attention, presence of visual and verbal feedback, and high motivation of the subjects to perform the task over the $6 \mathrm{wk}$ training period resulted in a significant OMT effect. These ideas are further supported by a recent study [42] that evaluated the neurological changes using the functional magnetic resonance imaging technique in two individuals with mTBI before and after intensive vergence-based OMT. Their results showed increased amount of voxels and correlation within specific regions of interest (brain stem, cerebellum, frontal eye fields, and supplementary eye fields) following a total of $18 \mathrm{~h}$ of clinically based and laboratory-based vergence OR, similar in nature to that conducted in the present study. Their results also correlated with increased vergence peak velocity, as found in the present study. The increased convergence peak velocity was found to correlate with an increase in amount of active voxels and correlation within the brain stem, cerebellum, and frontal lobe regions. While the NPC was correlated with the brain stem activity, the PFV amplitude was correlated with frontal, parietal, and cerebellar regions. Increased cortical activity was suggested to be due to "neural recruitment" in the previously specified regions, and the correlation was attributed to "improved synchronization" of the involved subsystems vergence neurons [42]. These findings provide further direct neurological support for the proposed neurological process involved in our OMT (Figures 5-6).

\section{CONCLUSIONS}

Vergence-based OR was effective in individuals with mTBI who reported nearwork-related symptoms. Overall improvement in nearly all of the critical, abnormal measures of vergence was observed both objectively and clinically. Improved vergence motor control was attributed to residual neural visual system plasticity and oculomotor learning effects in these individuals. Concurrently, nearwork-related symptoms reduced, and visual attention improved.

\section{ACKNOWLEDGMENTS}

Author Contributions:

Study concept and design: P. Thiagarajan, K. J. Ciuffreda.
Acquisition of data: P. Thiagarajan.

Analysis and interpretation of data: P. Thiagarajan, K. J. Ciuffreda.

Drafting of manuscript: P. Thiagarajan.

Critical revision of manuscript for important intellectual content:

P. Thiagarajan, K. J. Ciuffreda.

Statistical analysis: P. Thiagarajan.

Obtained funding: K. J. Ciuffreda.

Administrative, technical, or material support: K. J. Ciuffreda.

Study supervision: K. J. Ciuffreda.

Financial Disclosures: The authors have declared that no competing interests exist.

Funding/Support: This material was based on work supported by the U.S. Army, Department of Defense (Telemedicine and Advanced Technology Research Center awards W81XWH-10-1-1041 and W81XWH-12-1-0240), College of Optometrists in Vision Development, and SUNY College of Optometry Graduate Program.

Additional Contributions: We would also like to thank Dr. Neera Kapoor for subject recruitment, Dr. José E. Capó-Aponte for his help in the proposal writing, and Ms. Diana Ludlam and Mr. Naveen Yadav for their help during testing. Dr. Thiagarajan is now with the Retina Foundation of the Southwest, Dallas, Texas.

Institutional Review: The study was approved by the SUNY Institutional Review Board and U.S. Army Medical Research and Materiel Command, Office of Research Protections, Human Research Protection Office. Written informed consent was obtained from all subjects prior to their participation.

Participant Follow-Up: We do not plan to inform participants of the publication of this study. However, they have been encouraged to check PubMed (http://www.ncbi.nlm.nih.gov/pubmed/) for study publications.

\section{REFERENCES}

1. Management of Concussion/mTBI Working Group. VA/ DoD clinical practice guideline for management of concussion/mild traumatic brain injury. J Rehabil Res Dev. 2009; 46(6):CP1-68. [PMID:20108447]

2. Coronado VGT, Faul M, Wald MM, Xu L; National Center for Injury Prevention and Control, U.S. Division of Injury Response. Traumatic brain injury in the United States: Emergency department visits, hospitalizations, and deaths, 20022006. Atlanta (GA): Department of Health and Human Services, Centers for Disease Control and Prevention, National Center for Injury Prevention and Control; 2010.

3. Suchoff IB, Kapoor N, Ciuffreda KJ. An overview of acquired brain injury and optometric implications. In: Suchoff IB, Ciuffreda KJ, Kapoor N, editors. Visual and vestibular consequences of acquired brain injury. Santa Ana (CA): Optometric Extension Program Foundation; 2001.

4. Kraus JF, McArthur DL, Silberman TA. Epidemiology of mild brain injury. Semin Neurol. 1994;14(1):1-7.

[PMID:8029555]

http://dx.doi.org/10.1055/s-2008-1041052 
5. Arlinghaus KA, Pastorek NJ, Graham DP. Neuropsychiatric assessment. In: Silver JM, McAllister TW, Yudofsky SC, editors. Textbook of traumatic brain injury. 2nd ed. Arlington (VA): American Psychiatric Publishing; 2011. p. 55-72.

6. Helvie R. Neural substrates of vision. In: Suter PS, Harvey LH, editors. Vision rehabilitation: Multidisciplinary care of the patient following brain injury. Boca Raton (FL): CRC Press, Taylor and Francis Group; 2011.

7. Ciuffreda KJ, Kapoor N, Rutner D, Suchoff IB, Han ME, Craig S. Occurrence of oculomotor dysfunctions in acquired brain injury: A retrospective analysis. Optometry. 2007; 78(4):155-61. [PMID:17400136] http://dx.doi.org/10.1016/j.optm.2006.11.011

8. Ciuffreda KJ, Han Y, Kapoor N, Ficarra AP. Oculomotor rehabilitation for reading in acquired brain injury. NeuroRehabilitation. 2006;21(1):9-21. [PMID:16720933]

9. Ciuffreda KJ, Tannen B. Eye movement basics for the clinician. St. Louis (MO): Mosby; 1995.

10. Ciuffreda KJ. Components of clinical near vergence testing. J Behav Optom. 1992;3(1):3-13.

11. Leigh JR, Zee DS. The neurology of eye movements. 4th ed. New York (NY): Oxford University Press; 2006.

12. Mays LE. Neural control of vergence eye movements: Convergence and divergence neurons in midbrain. J Neurophysiol. 1984;51(5):1091-1108. [PMID:6726313]

13. Rambold H, Neumann G, Helmchen C. Vergence deficits in pontine lesions. Neurology. 2004;62(10):1850-53. [PMID:15159493] http://dx.doi.org/10.1212/01.WNL.0000125331.95849.62

14. Rambold H, Neumann G, Sander T, Helmchen C. Pontine lesions may cause selective deficits of "slow" vergence eye movements. Ann N Y Acad Sci. 2005;1039:567-70. [PMID:15827024] http://dx.doi.org/10.1196/annals.1325.069

15. Westheimer G, Blair SM. Oculomotor defects in cerebellectomized monkeys. Invest Ophthalmol. 1973;12(8):618-21. [PMID:4200441]

16. Gamlin PD, Yoon K. An area for vergence eye movement in primate frontal cortex. Nature. 2000;407(6807): 1003-7. [PMID:11069179] http://dx.doi.org/10.1038/35039506

17. Gnadt JW, Mays LE. Neurons in monkey parietal area LIP are tuned for eye-movement parameters in three-dimensional space. J Neurophysiol. 1995;73(1):280-97. [PMID:7714572]

18. Genovesio A, Ferraina S. Integration of retinal disparity and fixation-distance related signals toward an egocentric coding of distance in the posterior parietal cortex of primates. J Neurophysiol. 2004;91(6):2670-84.

[PMID:14960558] http://dx.doi.org/10.1152/jn.00712.2003
19. DeAngelis GC, Cumming BG, Newsome WT. Cortical area MT and the perception of stereoscopic depth. Nature. 1998; 394(6694):677-80. [PMID:9716130]

http://dx.doi.org/10.1038/29299

20. Takemura A, Inoue Y, Kawano K, Quaia C, Miles FA. Single-unit activity in cortical area MST associated with disparity-vergence eye movements: Evidence for population coding. J Neurophysiol. 2001;85(5):2245-66.

[PMID:11353039]

21. Prince SJ, Pointon AD, Cumming BG, Parker AJ. The precision of single neuron responses in cortical area $\mathrm{V} 1$ during stereoscopic depth judgments. J Neurosci. 2000;20(9): 3387-3400. [PMID:10777801]

22. Goodrich GL, Kirby J, Cockerham G, Ingalla SP, Lew HL. Visual function in patients of a polytrauma rehabilitation center: A descriptive study. J Rehabil Res Dev. 2007;44(7): 929-36. [PMID:18075950] http://dx.doi.org/10.1682/JRRD.2007.01.0003

23. Lew HL, Poole JH, Vanderploeg RD, Goodrich GL, Dekelboum S, Guillory SB, Sigford B, Cifu DX. Program development and defining characteristics of returning military in a VA Polytrauma Network Site. J Rehabil Res Dev. 2007; 44(7):1027-34. [PMID:18075959]

http://dx.doi.org/10.1682/JRRD.2007.05.0073

24. Brahm KD, Wilgenburg HM, Kirby J, Ingalla S, Chang CY, Goodrich GL. Visual impairment and dysfunction in combat-injured servicemembers with traumatic brain injury. Optom Vis Sci. 2009;86(7):817-25. [PMID:19521270] http://dx.doi.org/10.1097/OPX.0b013e3181adff2d

25. Stelmack JA, Frith T, Van Koevering D, Rinne S, Stelmack TR. Visual function in patients followed at a Veterans Affairs polytrauma network site: An electronic medical record review. Optometry. 2009;80(8):419-24.

[PMID:19635432] http://dx.doi.org/10.1016/j.optm.2009.02.011

26. Capó-Aponte JE, Tarbett AK, Urosevich TG, Temme LA, Sanghera NK, Kalich ME. Effectiveness of computerized oculomotor vision screening in a military population: Pilot study. J Rehabil Res Dev. 2012;49(9):1377-98.

[PMID:23408219] http://dx.doi.org/10.1682/JRRD.2011.07.0128

27. Goodrich GL, Flyg HM, Kirby JE, Chang CY, Martinsen GL. Mechanisms of TBI and visual consequences in military and veteran populations. Optom Vis Sci. 2013;90(2): 105-12. [PMID:23314131] http://dx.doi.org/10.1097/OPX.0b013e31827f15a1

28. Capó-Aponte JE, Urosevich TG, Temme LA, Tarbett AK, Sanghera NK. Visual dysfunctions and symptoms during the subacute stage of blast-induced mild traumatic brain injury. Mil Med. 2012;177(7):804-13. [PMID:22808887]

29. Bulson R, Jun W, Hayes J. Visual symptomatology and referral patterns for Operation Iraqi Freedom and Operation 
Enduring Freedom veterans with traumatic brain injury. J Rehabil Res Dev. 2012;49(7):1075-82.

[PMID:23341280]

http://dx.doi.org/10.1682/JRRD.2011.02.0017

30. Cross AG. Neuromuscular aspects in ocular sequelae of head injuries. Trans Ophthalmol Soc UK. 1945;65:20-33.

31. Cross AG. The ocular sequelae of head injury. Ann R Coll Surg Engl. 1948;2(5):233-40. [PMID:18859709]

32. Thiagarajan P, Ciuffreda KJ, Ludlam DP. Vergence dysfunction in mild traumatic brain injury (mTBI): A review. Ophthalmic Physiol Opt. 2011;31(5):456-68.

[PMID:21410499] http://dx.doi.org/10.1111/j.1475-1313.2011.00831.x

33. Krohel GB, Kristan RW, Simon JW, Barrows NA. Posttraumatic convergence insufficiency. Ann Ophthalmol. 1986; 18(3):101-2, 104. [PMID:3963678]

34. Cohen M, Groswasser Z, Barchadski R, Appel A. Convergence insufficiency in brain-injured patients. Brain Inj. 1989;3(2):187-91. [PMID:2471568] http://dx.doi.org/10.3109/02699058909004551

35. Suchoff IB, Kapoor N, Waxman R, Ference W. The occurrence of ocular and visual dysfunctions in an acquired brain-injured patient sample. J Am Optom Assoc. 1999; 70(5):301-8. [PMID:10457707]

36. Hellerstein LF, Freed S, Maples WC. Vision profile of patients with mild brain injury. J Am Optom Assoc. 1995; 66(10):634-39. [PMID:7499718]

37. al-Qurainy IA. Convergence insufficiency and failure of accommodation following midfacial trauma. $\mathrm{Br} \mathrm{J}$ Oral Maxillofac Surg. 1995;33(2):71-75. [PMID:7772590] http://dx.doi.org/10.1016/0266-4356(95)90203-1

38. Schlageter K, Gray B, Hall K, Shaw R, Sammet R. Incidence and treatment of visual dysfunction in traumatic brain injury. Brain Inj. 1993;7(5):439-48. [PMID:8401486] http://dx.doi.org/10.3109/02699059309029687

39. Berne SA. Visual therapy for the traumatic brain-injured. J Optom Vis Dev. 1990;21:13-16.

40. Ron S, Najenson T, Hary D, Pryworkin W. Eye movements in brain damaged patients. Scand J Rehabil Med. 1978; 10(1):39-44. [PMID:644262]

41. Szymanowicz D, Ciuffreda KJ, Thiagarajan P, Ludlam DP, Green W, Kapoor N. Vergence in mild traumatic brain injury: A pilot study. J Rehabil Res Dev. 2012;49(7):10831100. [PMID:23341281] http://dx.doi.org/10.1682/JRRD.2010.07.0129

42. Alvarez TL, Vicci VR, Alkan Y, Kim EH, Gohel S, Barrett AM, Chiaravalloti N, Biswal BB. Vision therapy in adults with convergence insufficiency: Clinical and functional magnetic resonance imaging measures. Optom Vis Sci. 2010;87(12):E985-1002. [PMID:21057347] http://dx.doi.org/10.1097/OPX.0b013e3181feflaa
43. Chandler R. Some observations on orthoptic treatment following head injury. Br Orthoptic J. 1944;2:56-62.

44. Cohen AH. Optometric management of binocular dysfunctions secondary to head trauma: Case reports. J Am Optom Assoc. 1992;63(8):569-75. [PMID:1512408]

45. Hellerstein LF, Freed S. Rehabilitative optometric management of a traumatic brain injury patient. J Behav Opt. 1994; 5(6):143-48.

46. Ludlam WM. Rehabilitation of traumatic brain injury with associated visual dysfunction-A case report. NeuroRehabilitation. 1996;6(3):183-92. http://dx.doi.org/10.1016/1053-8135(96)00164-3

47. Kerkhoff G, Stögerer E. Recovery of fusional convergence after systematic practice. Brain Inj. 1994;8(1):15-22. [PMID:8124313] http://dx.doi.org/10.3109/02699059409150955

48. Ciuffreda KJ, Rutner D, Kapoor N, Suchoff IB, Craig S, Han ME. Vision therapy for oculomotor dysfunctions in acquired brain injury: A retrospective analysis. Optometry. 2008;79(1):18-22. [PMID:18156092]

http://dx.doi.org/10.1016/j.optm.2007.10.004

49. Scheiman M, Gallaway M. Vision therapy to treat binocular vision disorders after acquired brain injury: Factors affecting prognosis. In: Suchoff IB, Ciuffreda KJ, Kapoor $\mathrm{N}$, editors. Visual and vestibular consequences of acquired brain injury. Santa Ana (CA): Optometric Extension Program; 2001.

50. Abernethy B, Hanrahan S, Kippers V, Mackinnon LT, Pandy MG. The biophysical foundations of human movement. Champaign (IL): Human Kinetics; 2005. p. 51.

51. Ciuffreda KJ. The scientific basis for and efficacy of optometric vision therapy in nonstrabismic accommodative and vergence disorders. Optometry. 2002;73(12):735-62. [PMID:12498561]

52. Reding MJ, Potes E. Rehabilitation outcome following initial unilateral hemispheric stroke. Life table analysis approach. Stroke. 1988;19(11):1354-58. [PMID:3188120] http://dx.doi.org/10.1161/01.STR.19.11.1354

53. Groswasser Z, Cohen M, Blankstein E. Polytrauma associated with traumatic brain injury: incidence, nature and impact on rehabilitation outcome. Brain Inj. 1990;4(2): 161-66. [PMID:2331545] http://dx.doi.org/10.3109/02699059009026161

54. Han Y, Ciuffreda KJ, Kapoor N. Reading-related oculomotor testing and training protocols for acquired brain injury in humans. Brain Res Brain Res Protoc. 2004;14(1):1-12. [PMID:15519946] http://dx.doi.org/10.1016/j.brainresprot.2004.06.002

55. Kapoor N, Ciuffreda KJ, Han Y. Oculomotor rehabilitation in acquired brain injury: A case series. Arch Phys Med Rehabil. 2004;85(10):1667-78. [PMID:15468029] http://dx.doi.org/10.1016/j.apmr.2003.12.044 
56. Chen H, Epstein J, Stern E. Neural plasticity after acquired brain injury: Evidence from functional neuroimaging. PM R. 2010;2(12 Suppl 2):S306-12. [PMID:21172692] http://dx.doi.org/10.1016/j.pmrj.2010.10.006

57. Benjamin WJ. Borish's clinical refraction. 2nd ed. Oxford (England): Butterworth-Heinemann; 2006.

58. Green W, Ciuffreda KJ, Thiagarajan P, Szymanowicz D, Ludlam DP, Kapoor N. Accommodation in mild traumatic brain injury. J Rehabil Res Dev. 2010;47(3):183-99. [PMID:20665345] http://dx.doi.org/10.1682/JRRD.2009.04.0041

59. Khan AA. Digital signal processing fundamentals. Hingham (MA): Da Vinci Engineering Press; 2005.

60. Trenerry MR, Crosson B, DeBoe J, Leber WR. Visual Search and Attention Test: Professional manual. Odessa (FL): Psychological Assessment Resources; 1990.

61. Rouse MW, Borsting EJ, Mitchell GL, Scheiman M, Cotter SA, Cooper J, Kulp MT, London R, Wensveen J; Convergence Insufficiency Treatment Trial Group. Validity and reliability of the revised Convergence Insufficiency Symptom Survey in adults. Ophthalmic Physiol Opt. 2004;24(5): 384-90. [PMID:15315652] http://dx.doi.org/10.1111/j.1475-1313.2004.00202.x

62. Scheiman M, Wick B. Clinical management of binocular vision: Heterophoric, accommodative, and eye movement disorders. 3rd ed. Philadelphia (PA): Wolters Kluwer Health/Lippincott, Williams, and Wilkins; 2008.

63. Schor CM. Fixation disparity and vergence adaptation. In: Schor CM, Ciuffreda KJ, editors. Vergence eye movements: Basic and clinical aspects. Boston (MA): Butterworth; 1983. p. 484-88.

64. Thiagarajan P, Lakshminarayanan V, Bobier WR. Effect of vergence adaptation and positive fusional vergence training on oculomotor parameters. Optom Vis Sci. 2010;87(7): 487-93. [PMID:20473234]

65. Rashbass C, Westheimer G. Disjunctive eye movements. J Physiol. 1961;159:339-60. [PMID:14490420]

66. Hung GK, Zhu H, Ciuffreda KJ. Convergence and divergence exhibit different response characteristics to symmetric stimuli. Vision Res. 1997;37(9):1197-1205.

[PMID:9196737] http://dx.doi.org/10.1016/S0042-6989(97)00271-X

67. Semmlow JL, Hung GK, Horng JL, Ciuffreda K. Initial control component in disparity vergence eye movements. Ophthalmic Physiol Opt. 1993;13(1):48-55.

[PMID:8510948] http://dx.doi.org/10.1111/j.1475-1313.1993.tb00426.x

68. North RV, Henson DB. Adaptation to prism-induced heterophoria in subjects with abnormal binocular vision or asthenopia. Am J Optom Physiol Opt. 1981;58(9):746-52. [PMID:7294146]
69. Vaegan. Convergence and divergence show large and sustained improvement after short isometric exercise. Am J Optom Physiol Opt. 1979;56(1):23-33. [PMID:484701]

70. Rosenfield M. Tonic vergence and vergence adaptation. Optom Vis Sci. 1997;74(5):303-28. [PMID:9219290] http://dx.doi.org/10.1097/00006324-199705000-00027

71. Manas L. The effect of visual training upon the ACA ratio. Am J Optom Arch Am Acad Optom. 1958;35(8):428-37. [PMID:13571370]

72. Fisher SK, Ciuffreda KJ. Adaptation to optically-increased interocular separation under naturalistic viewing conditions. Perception. 1990;19(2):171-80. [PMID:2235285] http://dx.doi.org/10.1068/p190171

73. Brautaset RL, Jennings AJ. Effects of orthoptic treatment on the $\mathrm{CA} / \mathrm{C}$ and $\mathrm{AC} / \mathrm{A}$ ratios in convergence insufficiency. Invest Ophthalmol Vis Sci. 2006;47(7):2876-80. [PMID:16799027] http://dx.doi.org/10.1167/iovs.04-1372

74. Ciuffreda KJ, Ludlam DP, Thiagarajan P. Oculomotor diagnostic protocol for the mTBI population. Optometry. 2011; 82(2):61-63. [PMID:21276567]

http://dx.doi.org/10.1016/j.optm.2010.11.011

75. Yuan W, Semmlow JL, Alvarez TL, Munoz P. Dynamics of the disparity vergence step response: A model-based analysis. IEEE Trans Biomed Eng. 1999;46(10):1191-98.

[PMID:10513123]

http://dx.doi.org/10.1109/10.790495

76. Semmlow JL, Yuan W. Components of disparity vergence eye movements: Application of independent component analysis. IEEE Trans Biomed Eng. 2002;49(8):805-11.

[PMID:12148819] http://dx.doi.org/10.1109/TBME.2002.800758

77. Mays LE, Porter JD, Gamlin PD, Tello CA. Neural control of vergence eye movements: Neurons encoding vergence velocity. J Neurophysiol. 1986;56(4):1007-21. [PMID:3783225]

78. Keller EL. Participation of medial pontine reticular formation in eye movement generation in monkey. J Neurophysiol. 1974;37(2):316-32. [PMID:4205567]

79. Gamlin PD. Neural mechanisms for the control of vergence eye movements. Ann N Y Acad Sci. 2002;956:264-72. [PMID:11960810] http://dx.doi.org/10.1111/j.1749-6632.2002.tb02825.x

80. Citri A, Malenka RC. Synaptic plasticity: Multiple forms, functions, and mechanisms. Neuropsychopharmacology. 2008;33(1):18-41. [PMID:17728696] http://dx.doi.org/10.1038/sj.npp.1301559

81. Johnston MV. Plasticity in the developing brain: Implications for rehabilitation. Dev Disabil Res Rev. 2009;15(2): 94-101. [PMID:19489084] http://dx.doi.org/10.1002/ddrr.64 
82. Hebb DO. The organization of behavior: A neuropsychological theory. New York (NY): Wiley; 1949.

83. Warraich Z, Kleim JA. Neural plasticity: The biological substrate for neurorehabilitation. PM R. 2010;2(12 Suppl 2): S208-19. [PMID:21172683] http://dx.doi.org/10.1016/j.pmrj.2010.10.016

84. Nakamura T, Hillary FG, Biswal BB. Resting network plasticity following brain injury. PLoS One. 2009;4(12):e8220. [PMID:20011533] http://dx.doi.org/10.1371/journal.pone.0008220

85. Bazarian JJ, Zhong J, Blyth B, Zhu T, Kavcic V, Peterson D. Diffusion tensor imaging detects clinically important axonal damage after mild traumatic brain injury: A pilot study. J Neurotrauma. 2007;24(9):1447-59. [PMID:17892407] http://dx.doi.org/10.1089/neu.2007.0241

86. Bigler ED. Anterior and middle cranial fossa in traumatic brain injury: Relevant neuroanatomy and neuropathology in the study of neuropsychological outcome. Neuropsychology. 2007;21(5):515-31. [PMID:17784800] http://dx.doi.org/10.1037/0894-4105.21.5.515
87. Thiagarajan P. Oculomotor rehabilitation for reading dysfunction in mild traumatic brain injury [dissertation]. New York (NY): State University of New York College of Optometry; 2012.

Submitted for publication December 28, 2012. Accepted in revised form June 11, 2013.

This article and any supplementary material should be cited as follows:

Thiagarajan P, Ciuffreda KJ. Effect of oculomotor rehabilitation on vergence responsivity in mild traumatic brain injury. J Rehabil Res Dev. 2013;50(9):1223-40.

http://dx.doi.org/10.1682/JRRD.2012.12.0235

ResearcherID/ORCID: Preethi Thiagarajan, BS Optom, MS, PhD: M-2337-2013

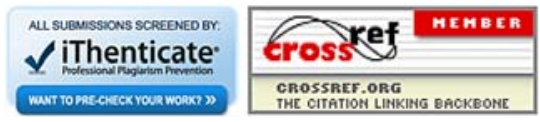


